\title{
DOCÊNCIA ONLINE: RELATO DE UMA EXPERIÊNCIA EM UM CURSO DE POSGRADUAÇÃO LATO SENSU
}

\author{
Joana Viana de Barros* \\ Leonardo Villela de Castro **
}

\begin{abstract}
RESUMO
O presente trabalho tem como objetivo realizar uma análise da docência online no contexto do modelo pedagógico de dois cursos de Especialização do Programa Nacional de Administração Pública (PNAP) na UNIRIO, assim como discutir as especificidades da docência no âmbito dessa modalidade. Contextualizase a vinculação dos cursos com o programa e verifica-se o deslocamento das atividades docentes no espaço-tempo em que elas são desempenhadas por diferentes atores ao longo do planejamento e da implementação do processo de ensino-aprendizagem. Propõe-se, neste estudo, que a docência online seja compreendida como uma atividade coletiva e colaborativa, na qual os atores compartilham as atribuições da atividade docente, conforme proposto por Mill et al. (2010). E, ainda, que ante as especificidades, novas habilidades sejam demandadas na atividade docente, na modalidade a distância, quando comparada com a modalidade presencial. Destaca-se, ainda, que essas especificidades devem ser consideradas nas discussões a respeito da profissionalização do docente.
\end{abstract}

Palavras-chave: Educação a distância. Docência online. Modelo pedagógico.

\begin{abstract}
This paper aims to conduct an analysis of online teaching in the context of the pedagogical model of two courses of specialization of the National Public Administration (PNAP) in UNIRIO well as discussing the specifics of their teaching within the discipline. Contextualizes the binding of the courses with the program and there is a shift in the space-time teachers where these activities are performed by different actors throughout the planning and implementation of the teaching-learning process. Proposed in this study that online teaching is understood as a collective and collaborative activity, where the actors share the responsibilities of teaching, as proposed by Miller (Miller et al 2010). And yet, that before the specific, new skills are demanded as a teacher in the distance when compared with the face modality. It is noteworthy also that these characteristics should be considered in discussions about the professionalization of teaching.
\end{abstract}

Keywords: Distance education. Online teaching. Teaching model

\footnotetext{
* Técnica em Assuntos educacionais - CEAD/UNIRIO.

${ }^{* *}$ Professor assistente - UNIRIO.
} 


\section{Introdução}

As recentes políticas de formação continuada, no âmbito federal, têm privilegiado a modalidade a distância com forte apoio das Tecnologias de Informação e Comunicação, as TICs. Esse modelo iniciou-se logo após a promulgação da LDB 9394/96, que definiu, no seu Art. 80, que "o Poder Público incentivará o desenvolvimento e a veiculação de programas de ensino a distância, em todos os níveis e modalidades de ensino, e de educação continuada" (grifo nosso). Posteriormente, esse artigo foi regulamentado pelo Decreto 5622, de 2005, que estabelece as diretrizes para o oferecimento de cursos na modalidade a distância. Nesse mesmo ano o governo cria, no âmbito do Plano de Desenvolvimento da Educação, a Universidade Aberta do Brasil - UAB, que tem como finalidade principal realizar formações de amplo alcance.

No início da oferta de cursos de educação a distância o alvo principal de tais políticas foi a formação inicial e continuada de professores. Ainda que esse alvo na área de formação de professores persista nos dias de hoje, em 2009 houve uma ampliação das ações de formação continuada para o funcionalismo público, em todas as esferas de poder. Entende-se que os serviços públicos e a sua gestão devem ser modernizados e, por essa razão, precisam assumir gradativamente a lógica da gestão privada, seus parâmetros de eficiência e eficácia, adequando-se esse setor à lógica de modernização conservadora em curso. (BARRETO, 2009).

No presente caso analisado, a CAPES, a SEED/MEC, a Escola Nacional de Administração Pública - ENAP e o Ministério da Saúde se juntaram e criaram o Programa Nacional de Formação em Administração Pública - PNAP. Esses órgãos definiram os profissionais e áreas em que era prioritária a formação dos servidores públicos da ativa. Em seguida, elaboraram os Projetos Político-Pedagógicos para cada curso dessas áreas, com suas grades curriculares e períodos de realização. A partir da definição do Programa foi nomeada uma comissão editorial para coordenar a produção do material didático. A Equipe de Desenvolvimento de Materiais do Departamento de Ciências da Administração do Centro Socioeconômico da Universidade Federal de Santa Catarina ficou responsável pela editoração.
A comissão convidou professores e técnicos de instituições públicas para escreverem o material impresso. Foram realizadas oficinas com os autores e, após a elaboração dos livros, os leitores de conteúdo avaliaram a pertinência dos mesmos com relação a quatro dimensões: estrutura, eficácia da aprendizagem, desenvolvimento curricular e avaliação. Após a elaboração desse material, formulou-se um edital em que concorreram diferentes Instituições de Ensino Superior Público, para se responsabilizarem pela implementação desses cursos e expedição dos respectivos diplomas.

A Universidade Federal do Estado do Rio de Janeiro - UNIRIO foi uma das que demonstrou condições e interesse em oferecer os cursos de Gestão Pública Municipal e Gestão de Organização Pública de Saúde. Compõem o quadro de docentes responsáveis pelo oferecimento dos cursos na instituição: o coordenador geral de cada curso, um coordenador de tutoria para cada curso, coordenadores de disciplina e professores-tutores dessas disciplinas. Estes últimos são responsáveis pelo contato direto com os alunos.

É dentro desse contexto, portanto, que este estudo ocorre, a partir da necessidade de entender a conformação desse quadro docente plural e polidocente. Ao relatar a pluralidade da docência em tal contexto específico, faz-se necessário analisar o seu modelo pedagógico quanto ao aspecto organizacional da docência, as atribuições dos atores envolvidos e o "momento" de participação de cada ator no processo.

Segundo o Decreto 5622, de 2005, a educação a distância é caracterizada como:

[...] modalidade educacional na qual a mediação didático-pedagógica nos processos de ensino e aprendizagem ocorre com a utilização de meios e tecnologias de informação e comunicação, com estudantes e professores desenvolvendo atividades educativas em lugares ou tempos diversos.

No entanto, há de se considerar que o redimensionamento do espaço e tempo na EaD não se restringe à relação entre professores e alunos, mas é estendido para a relação entre os docentes. No contexto da polidocência os atores participam da atividade docente em tempos e espaços diversos, compreendendo as diferentes atribuições dos sujeitos 
participantes no processo de ensino-aprendizagem. Nesse redimensionamento novas habilidades são mobilizadas para o desempenho das atividades docentes, algumas equivalentes às atividades desenvolvidas no atendimento presencial e outras vinculadas às especificidades da modalidade.

Inicia-se o texto pela discussão teórica sobre a docência, destacando-se a docência online. Em seguida, detalham-se as formas de organização da docência no âmbito dos cursos do PNAP, na UNIRIO, para, em seguida, analisá-lo à luz da teoria discutida. Por fim, elaboraram-se conclusões e sugestões tanto para o prosseguimento e melhoria dos cursos, como para o avanço da teoria relacionada à educação a distância.

\section{Metodologia}

$O$ relato de experiência é gênero textual acadêmico que tem sua aplicabilidade calcada na necessidade de refletir sobre práticas de projetos em execução, visando, sobretudo, ao aperfeiçoamento dos mesmos. Nesse sentido, é instrumento que possibilita a socialização de experiências comuns, dispersas no tempo e no espaço, e, como consequência, permite a formulação de teorias que reorientem determinado campo do conhecimento. Para os autores desse relato, "a noção de gênero considera, além dos elementos da ordem do social e do histórico, aspectos estruturais do texto, situação de produção e forma de dizer" (SILVA; LEITÃO, 2011).

$O$ relato foi realizado com base na observação participante, que, segundo Corsaro (2009, 85), "requer que o pesquisador não apenas observe repetidamente, mas também participe como membro do grupo".

Procurou-se, nos trechos descritos acima, esclarecer como se desenvolveu o presente relato, entendendo-se que o mesmo tem o seu contexto definido e sua forma apropriada, para que apresente o rigor necessário a uma produção científica, mas seja capaz de captar as tensões de um processo pedagógico em fase de instauração.

Os autores do presente trabalho foram responsáveis pelo assessoramento de todo o processo de ensino e aprendizagem de responsabilidade da CEAD/UNIRIO, o que incluiu: a) O planejamento junto aos coordenadores de curso e de tutoria, quando foi possível conhecer as expectativas dos mesmos e aprofundar o entendimento deles acerca da $\mathrm{EaD}$, de forma geral, e das necessidades de cada curso em particular.

b) O planejamento e execução dos processos de ambientação no ambiente virtual de aprendizagem (AVA) e a apresentação do projeto de curso aos coordenadores de disciplina e aos professores tutores. Nessas reuniões, das quais participaram também os coordenadores de curso e de tutoria, foi apresentada a proposta de trabalho e fez-se um levantamento das experiências desses atores em cursos a distancia. Foi possível observar algumas restrições e críticas dos coordenadores de disciplina a algumas práticas da EaD. Nessa primeira reunião é que se deu o primeiro contato desses docentes com a plataforma e-Uni, o que possibilitou também a percepção de algumas dificuldades desse ambiente virtual e, com base em propostas dos professores, o encaminhamento de solicitações de aperfeiçoamento para a equipe de desenvolvimento da plataforma.

c) $\mathrm{O}$ acompanhamento das reuniões quinzenais das equipes dos cursos e a implementação do sistema de avaliação dos cursos. Nessas reuniões quinzenais foi possível captar as dificuldades no uso de algumas ferramentas, bem como nos processos de comunicação e nos processos pedagógicos dos cursos. A atuação foi sempre no sentido de incentivar os professores-tutores a utilizar a linguagem mais coloquial no trato com os alunos.

Por todas essas inserções, e registrando sempre as observações feitas ao longo das mesmas, é que foi possível classificar a metodologia utilizada como observação participante, caracterizada pela autora citada.

\section{A DOCÊNCIA ONLINE}

Tardiff (2000) discute a epistemologia da prática profissional do professor a partir de um estudo sobre a natureza do saber docente. $\mathrm{O}$ autor elenca 
a temporalidade, a heterogeneidade e a personalização como especificidades do saber docente. Segundo Tardiff (2000), o saber docente é temporal, heterogêneo e personalizado. Temporal porque boa parte do que o professor sabe provém da sua própria história de vida como aluno; as suas experiências discentes contribuem como modelos para suas futuras atuações. Heterogêneo porque ele precisa atingir diferentes objetivos no seu cotidiano, no aspecto intrínseco tanto da aprendizagem dos conteúdos escolares, quanto dos aprendizados ligados à formação dos sujeitos para a convivência no meio social mais amplo. Por fim, é personalizado por ser influenciado pela sua cultura e pela sua própria história enquanto ator social, sendo esta, inclusive, uma de suas formas de contribuir para a construção de uma cultura escolar local.

Shulman (1986 apud MILL et al., 2010) afirma que a base do conhecimento docente é composta por diversos conhecimentos, entre eles: o conhecimento do conteúdo específico, conhecimento do conteúdo pedagógico e o conhecimento pedagógico do conteúdo. Mill (2010) entende que a docência é uma atividade multideterminada, que depende de fatores institucionais, culturais e individuais. Um ponto em que os autores concordam é que o fazer docente demanda a integração de saberes de diferentes naturezas e domínios epistemológicos.

No âmbito da docência online observa-se um acréscimo de outros saberes a serem incorporados às considerações de diversos autores a respeito do saber docente, e também uma nova gestão dos saberes. Isso porque as atividades docentes na $\mathrm{EaD}$, em contraponto com a educação presencial, são desenvolvidas em um sistema denominado polidocência (MILL et al., 2010), ou seja, por um grupo de docentes. Dentre os novos saberes que precisam ser incorporados pelos professores na modalidade a distância destaca-se o domínio das tecnologias de informação e comunicação, a gestão do tempo e o gerenciamento de uma equipe de professores-tutores.

\section{RIO}

\section{A DOCÊNCIA ON LINE NO PNAP UNI-}

Os cursos do programa PNAP foram oferecidos na forma de edital, para que as IES se candidatassem à adesão ao programa. Um dos objetivos dos cursos é:
[...] contribuir para que o gestor público desenvolva visão estratégica dos negócios públicos, a partir do estudo sistemático e aprofundado da realidade administrativa do governo ou de suas unidades produtivas. (BRASIL. PPP/PNAP, 2009, p.10).

De acordo com o próprio edital do programa, a construção do PNAP foi feita de forma coletiva e colaborativa. Contou com o envolvimento de várias universidades públicas integrantes do Sistema UAB, com a experiência dos coordenadores do Curso de Administração Piloto, com a participação do Conselho Federal de Administração, com profissionais da Escola Nacional de Administração Pública (ENAP) e com o Ministério da Saúde, por meio de especialistas da Fundação Oswaldo Cruz (FIOCRUZ).

O modelo de Educação a Distância adotado pela UNIRIO faz uso da plataforma Moodle customizada, a plataforma e-Uni, onde foi desenvolvido o Ambiente Virtual de Aprendizagem (AVA) com um forte predomínio de ferramentas de comunicação assíncronas. Nesse AVA cada professor tutor tem a sala de sua disciplina, cujo conteúdo e atividades são replicados de uma metadisciplina (organizada pelo coordenador da disciplina), da qual constam: o material elaborado sob a supervisão da UFSC, conforme descrito na introdução; um cronograma com todas as atividades a serem executadas pelos alunos; e um guia da disciplina, elaborado pelo coordenador, onde ele apresenta todo o curso e fornece orientações de estudo para os alunos.

No modelo de gestão adotado a equipe docente na UNIRIO é composta pelos coordenadores de disciplina e pelos professores tutores. Os coordenadores, além da elaboração já citada, têm acesso a todas as salas dos tutores que com eles partilham a responsabilidade pelo andamento da disciplina. Já os professores-tutores têm acesso apenas a sua sala de aula, onde interagem com os alunos e são responsáveis pelas correções das atividades, postagem das notas e orientações sobre dúvidas e avaliações.

\section{A equipe docente}

No presente trabalho entende-se por atividade docente aquela envolvida diretamente com o processo de ensino-aprendizagem.

De acordo com o modelo referido de polidocência, considerou-se parte integrante da equipe docente 
do curso o autor do material, o coordenador de disciplina e o professor-tutor. Os demais atores envolvidos no processo e representados no organograma abaixo devem, dentre outras atribuições, supervisionar e apoiar as atividades docentes e coordenar as atividades acadêmicas dos cursos.

Figura 1 - Organograma setorial da CEAD e os cursos PNAP/UNIRIO. ${ }^{1}$

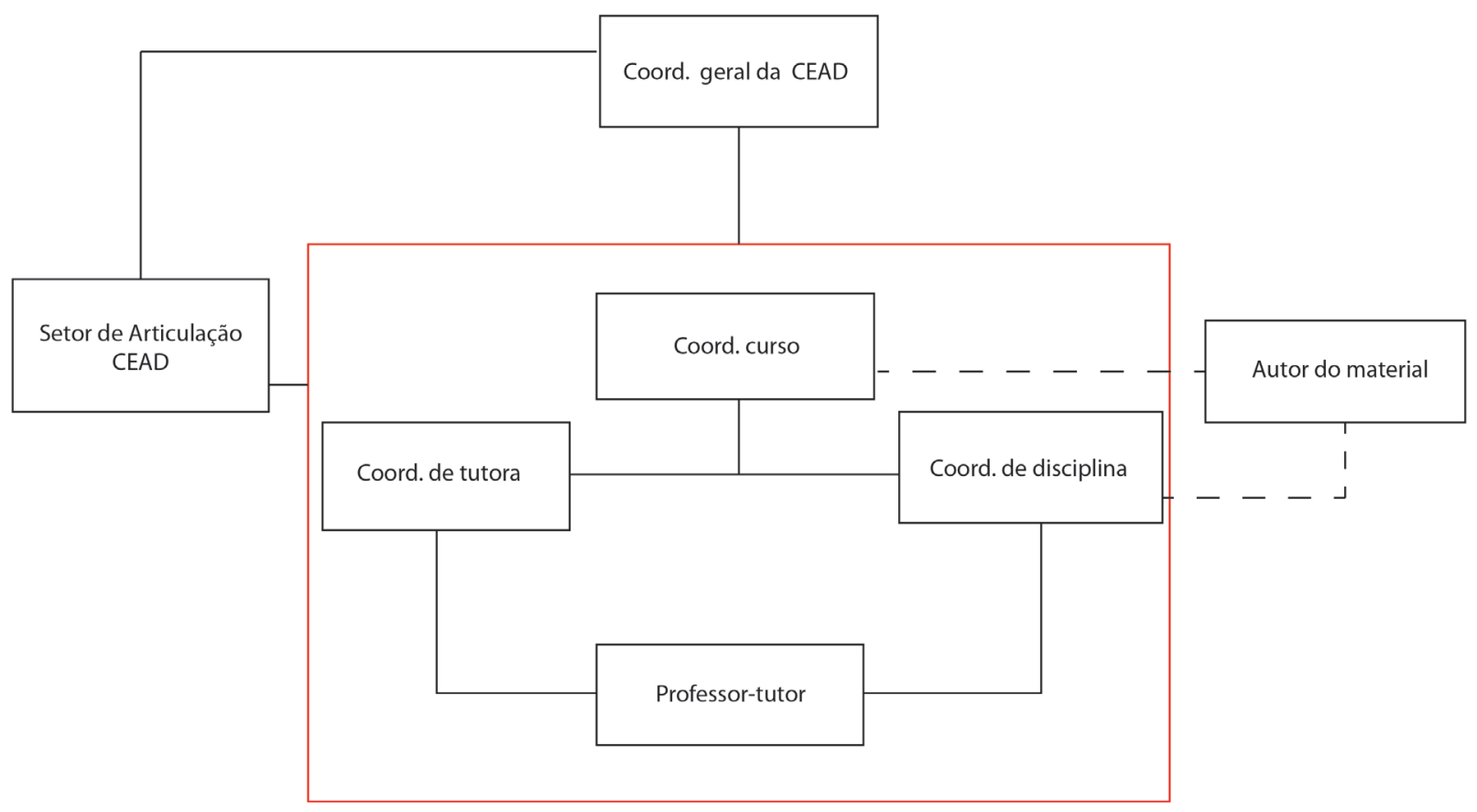

O coordenador de disciplina é nomeado entre os professores da própria universidade, preferencialmente; em caso de necessidade, convida-se algum professor de outra instituição pública com notório saber na área de conhecimento requerida. $\mathrm{O}$ professor-tutor participa de uma seleção pública e, em geral, não é servidor da instituição. $\mathrm{O}$ autor de materiais é selecionado pelo Sistema UAB em etapa anterior à adesão da Universidade ao programa. É importante destacar que na modalidade a distância o material didático é elaborado com a finalidade de que a aprendizagem se efetive prescindindo da presença do professor. Cada coordenador de disciplina levou a termo a sua tarefa docente coordenando equipes de, em média, dez professores tutores.

Ao considerar os autores de materiais como participantes da equipe docente nos apoiamos na proposta de produção de materiais específica para a EaD, na qual

[...] deve-se levar em conta a necessidade de dialogicidade, bem como de se constituir em material motivador do estudo, daí o tratamento do material a partir de uma linguagem comunicacional moderna, que instigue o indivíduo à pesquisa para além do material em questão. (BELISÁRIO, 2008, p. 146).

O que diferencia o material didático no sistema EaD é que este é concebido e produzido especificamente para o estudante e deve ter unidade, sentido e direção, além de se conectar com a proposta pedagógica do curso. Portanto, identifica-se na atividade de autoria do material um comprometimento direto com o processo de ensino-aprendizagem.

\footnotetext{
${ }^{1}$ No esquema acima os atores englobados pelo quadrado constituem a equipe responsável pela oferta do curso no âmbito das atividades acadêmicas e pedagógicas da instituição. Os atores destacados em cinza apresentam dentre as suas atribuições o desenvolvimento das atividades da docência do curso. Os demais atores apresentam, dentre as suas atribuições, a supervisão das atividades de docência, assim como o desenvolvimento das atividades acadêmicas do curso.
} 
Tabela 1 - As atribuições, vínculos e inserções dos atores-docentes no processo de ensino-aprendizagem no modelo pedagógico adotado.

\begin{tabular}{|l|c|c|c|}
\hline & AUTOR & PROFESSOR-TUTOR & $\begin{array}{c}\text { COORDENADOR DE } \\
\text { DISCIPLINA }\end{array}$ \\
\hline Atribuições principais & $\begin{array}{c}\text { Elaborar os materiais } \\
\text { didáticos com o objetivo } \\
\text { de promover a mediação } \\
\text { do conteúdo dos textos } \\
\text { com os alunos. }\end{array}$ & $\begin{array}{c}\text { Acompanhar o desempen- } \\
\text { ho dos alunos, avaliar as } \\
\text { atividades dos alunos. }\end{array}$ & $\begin{array}{c}\text { Coordenar as atividades } \\
\text { acadêmicas dos profes- } \\
\text { sores-tutores atuantes } \\
\text { nas disciplinas sob a sua } \\
\text { coordenação. }\end{array}$ \\
\hline Vínculo com a IFE & Nenhum & Vínculo precário & Em geral, docente \\
\hline $\begin{array}{l}\text { Inserção da sua intervenção } \\
\text { no espaço-tempo }\end{array}$ & Anterior à adesão da IES & Posterior à adesão da IES & Posterior à adesão da IES \\
\hline
\end{tabular}

No modelo apresentado, considera-se a docência online como o exercício da docência no espaço-tempo de interação com os alunos. Utiliza-se como suporte o AVA, que, no caso, é a plataforma e-Uni. Os autores de materiais, portanto, apesar de participarem da equipe docente, não fazem parte da equipe de docência online devido ao deslocamento desses atores responsáveis pela sistematização do conhecimento do conteúdo pedagógico para outro espaço-tempo, fora do contexto da docência propriamente dita. Por conta desse deslocamento, a adequabilidade e a pertinência dos materiais didáticos são discutidas na revalidação desse material pelos coordenadores de disciplina. São também discutidas alternativas para a sua mediação no contexto da docência online, de acordo com as finalidades de ensino.
As condições desses profissionais para assumir tais responsabilidades serão descritas a seguir. E, na análise que faremos mais adiante, ficarão evidentes as contradições que o processo enfrentou.

\section{As condições de trabalho}

$\mathrm{O}$ contrato de trabalho da equipe docente e dos envolvidos no oferecimento do curso, ou seja, dos coordenadores dos dois cursos, dos dois coordenadores de tutoria, dos coordenadores de disciplina e dos professores tutores, é feito através de sistema de bolsas da CAPES. Esse sistema prevê o pagamento somente após o início efetivo da disciplina, para os coordenadores de disciplina e professores tutores. A remuneração do corpo docente variou de acordo com a tabela 2 .

Tabela 2 - Remuneração do quadro docente PNAP

\begin{tabular}{|l|c|c|c|}
\hline \multicolumn{1}{|c|}{ Função } & Tempo de duração & Valor da bolsa (em R\$) & Valor total \\
\hline Coord. de Curso & 18 meses & $1.500,00$ & $27.000,00$ \\
\hline Coord. de Tutoria & 18 meses & $1.300,00$ & $23.400,00$ \\
\hline Professor Formador & 6 meses & $1.300,00$ & $7.800,00$ \\
\hline Coord. de Disciplina & 4 meses & $1.300,00$ & $5.200,00$ \\
\hline Coord. de Disciplina & 2 meses & $1.300,00$ & $2.600,00$ \\
\hline Professor tutor & 6 meses & 750,00 & $4.500,00$ \\
\hline Professor tutor & 4 meses & 750,00 & $3.000,00$ \\
\hline Professor tutor & 2 meses & 750,00 & $1.500,00$ \\
\hline
\end{tabular}

Após a estruturação das equipes de coordenadores de disciplinas e de professores tutores, estes participaram de reuniões de capacitação conduzida pela equipe de docentes e técnicos da CEAD/UNIRIO, com o objetivo de apresentá-los às especificidades da modalidade a distância e aos projetos dos cursos.
No primeiro encontro foram apresentados os objetivos, os tópicos principais do regulamento e o cronograma de eventos do curso. Em seguida, propôs-se uma imersão na plataforma e-Uni e foram discutidas suas funcionalidades e possibilidades. 
Para os coordenadores, a ênfase das discussões recai sobre a necessidade de elaboração dos elementos que orientarão os alunos no processo de ensino-aprendizagem, como o cronograma do curso e o guia da disciplina. Além disso, eles elaboram as atividades e determinam os prazos para que as mesmas sejam cumpridas. As planilhas de notas, que no e-Uni são geradas através da postagem das atividades, também foi conteúdo de destaque na imersão. O principal objetivo desse processo é que o AVA esteja completo para os tutores os utilizarem nas suas imersões.

Para os professores-tutores as ênfases eram as discussões relacionadas ao processo de interação online e às diversas ferramentas existentes no AVA, que propiciam as trocas com os alunos. Com a necessidade de retorno aos alunos após as correções das atividades, o processo de avaliação também foi conteúdo destacado na imersão.

Enquanto os coordenadores de disciplina planejaram e elaboraram as atividades a serem desenvolvidas ao longo da disciplina, os professores-tutores acompanharam o desempenho dos alunos nas atividades.

Houve também, como parte obrigatória do contrato de bolsista, a participação em reuniões de capacitação realizadas ao longo do curso, a cada quinze dias. Nessas reuniões de equipe os professores-tutores relatavam algumas dificuldades apresentadas pelos alunos na execução de determinadas atividades, dificuldades essas que, por vezes, apontavam para e necessidade de modificar a customização da plataforma, ou mesmo de repensar a sequência de atividades. Esse retorno passado aos coordenadores permitia a reelaboração conjunta de algumas situações de aprendizagem, como a ampliação de prazos de postagem de tarefas, simplificação de outras, acréscimo de perguntas aos questionários e sugestão de tópicos específicos de fóruns, buscando atender às necessidades de compreensão dos alunos. Dessa forma, o acompanhamento cotidiano dos alunos pelos professores-tutores foi importante para adequar os planos originais das disciplinas e reorientar as atividades propostas.

\section{Resultados e análises}

Em relação às tarefas docentes do curso, percebemos que houve uma recontextualização, segundo a concepção de Bernstein (1996), entre o momento "pré-docência online", de planejamento do curso e de elaboração do material didático; o momento de "docência online", de elaboração do plano de trabalho das disciplinas, com suas tarefas, exercícios, avaliações; e o momento de execução do plano elaborado. Para o autor, a recontextualização se constitui a partir da transferência de textos de um contexto para outro.

Conforme relatado anteriormente, o material didático foi elaborado para ser utilizado por qualquer município do Brasil, o que demandou um esforço de cada coordenador de disciplina no sentido de vincular os conteúdos teóricos às realidades social, econômica e cultural locais. Na avaliação do material didático, realizada pelos coordenadores de disciplina, houve conflitos entre as diferentes abordagens teóricas dos autores e as dos próprios coordenadores de disciplina. A impossibilidade de o coordenador de disciplina ter uma ascendência criativa sobre o material a ser utilizado trouxe dificuldades na elaboração dos planos de trabalho, que, por vezes, se multiplicaram em dificuldades dos professores tutores e, por fim, dos próprios alunos. Acresce a essas dificuldades o pouco tempo que tiveram os coordenadores de disciplina para amadurecerem suas propostas de trabalho.

Em relação ao tempo, é necessário destacar também as dificuldades para ambientação dos coordenadores na plataforma e-Uni. Embora a maioria deles já tivesse familiaridade com ferramentas de uso corrente na EaD, as especificidades da plataforma e-Uni necessitavam de um processo mais intenso de uso para uma adequada apropriação dos recursos e possibilidades por parte do coordenadores de disciplina e também dos professores tutores. Nesse sentido, a relação de trabalho - que era estabelecida através do pagamento de bolsas sem qualquer vinculação com a carga horária dos professores da instituição - e a não previsão de pagamento de bolsas na etapa de planejamento dificultaram uma dedicação maior de parte desses professores no processo de ambientação e de planejamento de suas disciplinas. Entraves dessa natureza trouxeram improvisações 
desnecessárias, dificuldades na gestão dos tempos e na elaboração das tarefas. Podemos apontar essas dificuldades como algumas das causas que podem ter levado à desmotivação de alguns alunos e, no limite, ao desligamento dos mesmos quando se perceberam sem condições para interagir e absorver os conteúdos de forma significativa.

A gestão compartilhada do processo pedagógico, por não ser uma prática corrente entre os professores das instituições de ensino superior, encontrou resistências ao longo de todo o desenrolar das disciplinas. É necessário observar também as dificuldades que a própria CEAD/UNIRIO teve para criar as aproximações necessárias entre esses sujeitos, principalmente devido ao vínculo precário de trabalho de ambos, o que impediu convocações antes do início do curso; ou mesmo para a realização de reuniões ao longo do curso, pois estas ampliariam a carga horária de trabalho de todos, sem a devida remuneração.

A polidocência, por sua vez, constitui um desafio para todos os envolvidos na docência online e representa uma mudança de relação entre o sujeito docente e o seu saber, o que pode apresentar uma difusão da identidade docente entre os membros da equipe polidocente. As atribuições do professor-tutor e as habilidades mobilizadas para o exercício de sua atividade configuraram a tendência desse ator em se identificar como professor, na acepção tradicional do termo, na medida em que este desenvolve efetivamente uma comunicação com os alunos e os atende nos seus anseios e nas suas dificuldades. Em contraponto, a autoridade do professor-tutor como especialista do conteúdo é fragilizada pelo próprio sistema, que apresenta dificuldade de recrutamento de especialistas para o exercício da atividade por conta da precariedade do vínculo e da baixa remuneração.

\section{Conclusões}

O presente trabalho, ao apresentar o modelo pedagógico adotado na experiência da UNIRIO, discute as relações docentes no contexto da polidocência e propõe novas discussões com relação aos desafios que emergem a partir da reconfiguração da docência na modalidade a distância.
Mesmo pontuando que a prática pedagógica sofreu transformações no cenário atual com o uso de TICs e com o atendimento a uma crescente demanda de formação continuada, devemos, ante essa mudança, reconhecer no modelo presencial original as tradicionais significâncias com o objetivo de refletir a respeito das razões das permanências e das transformações ocorridas. A questão docente é um ponto de reflexão importante nesse sentido.

A relação da educação a distância com uma educação centrada no sujeito segundo a concepção construtivista é defendida por alguns autores (SILVA, 2008). De fato, a modalidade a distância exige do aluno uma postura mais autônoma e pró-ativa, mas não acreditamos que a relação entre concepção construtivista e educação a distância seja direta e inevitável. A mediação da equipe docente é determinante na condução do processo de aprendizagem, e os saberes dessa equipe plural são, portanto, moduladores desse processo. $\mathrm{Na}$ equipe docente, as tomadas de decisão ao longo da prática docente podem ser centralizadas na figura de um determinado ator-docente, ou podem ser compartilhadas por toda a equipe. Um dos desafios da polidocência reside no seu próprio modelo, que demanda dos docentes a habilidade de trabalho em equipe e o compartilhamento de estratégias pedagógicas. Considerando que não é uma prática corrente entre os profissionais docentes o diálogo e o compartilhamento de ideias e ações, concluímos que a educação a distância promove a reconfiguração da docência.

No bojo da discussão a respeito da profissionalização do docente, verificamos que a modalidade a distância apresenta novos saberes ao repertório de saberes já identificado por alguns autores (SHULMAN, 1986; TARDIFF, 2000) no âmbito do saber docente. Mesmo que as atribuições dos atores-docentes se complementem e, de certa forma, não os sobrecarreguem, verifica-se, na prática, que cada ator-docente apresenta as suas práticas pedagógicas pulverizadas e corre o risco de perder a visão integral do processo quando há alguma deficiência nos fluxos de comunicação.

A esse risco de alienação soma-se a condição precária do trabalho, a baixa remuneração, aliada ao sistema de contratação por via de bolsas, que dificulta a criação de um vínculo mais intenso de todos os professores-tutores que assumem as diversas funções 
docentes. Embora na experiência descrita os sujeitos que executaram as tarefas de coordenadores e de professores-tutores tenham se empenhado e se mostrado interessados na aprendizagem dos alunos, o fato de só se poder contar com a presença desses sujeitos nas vésperas do início do curso dificultou uma imersão mais adequada no AVA. Além disso, impediu uma apropriação adequada do conteúdo com o qual eles trabalharam e, da parte dos coordenadores de disciplina, não permitiu uma reflexão crítica adequada ao material recebido. Todos esses fatores contribuíram para ampliar dificuldades surgidas ao longo do processo, como o questionamento de alguns alunos a respeito de contradições entre o conteúdo do material e as leituras complementares, e a orientação dos professores-tutores aos alunos em relação ao uso adequado do ambiente virtual, por exemplo.

Para os autores deste trabalho ficou evidente, mais uma vez, a necessidade dos projetos na modalidade EAD demandarem uma organização bastante detalhada de todos os procedimentos necessários e um envolvimento intenso de todos os sujeitos, sejam eles docentes ou membros da equipe de apoio, em todas as etapas do planejamento e de execução do programa. Para alcançar esse patamar de atuação devem ser redefinidas as atuais linhas de ação das políticas públicas para a área, valorizando-se o trabalho docente em todas as suas dimensões e propiciando condições para que o mesmo seja exercido na sua plenitude.

\section{Referências}

BARRETO, R.G. Discursos, tecnologia, educação. Rio de Janeiro: EDUERJ, 2009.

BELISÁRIO, A. O material didático na educação a distância e a constituição de propostas interativas. In: SILVA, M. Educação online: teorias, práticas, legislação, formação corporativa. Rio de Janeiro: Ed. Loyola. 2009. p.137-148.

BERNSTEIN, B. A estruturação do discurso pedagógico: classe, códigos e controle. Petrópolis: Vozes, 1996.

BRASIL. Decreto $n^{\circ}$ 5622, de 9 de dezembro de 2005. Regulamenta o art. 80 da Lei $n^{\circ}$. 9.394, de 20 de dezembro de 1996, que estabelece as diretrizes e bases da educação nacional. Diário Oficial [da] República Federativa do Brasil, Brasília, DF, 10 dez. 2005. Disponível em: http:// www.planalto.gov.br/ccivil_03/_Ato2004-2006/2005/ Decreto/D5622.htm. Acesso em: 15 fev. 2012.
BRASIL. MEC/UAB. Projeto pedagógico do curso de pós-graduação lato sensu em gestão municipal. 2009. Disponível em: http://www.capes.gov.br/educacao-adistancia/pnap. Acesso em: 15 fev. 2012.

CORSARO, W. Métodos etnográficos no estudo da cultura de pares e das transições iniciais na vida das crianças: diálogos com William Corsaro. In: MULLER, F.; CARVALHO, A. M. (Org.). Teoria e prática de pesquisa com crianças. São Paulo: Cortez, 2009.

MILL, D. Sobre o conceito de polidocência ou sobre a natureza do processo de trabalho pedagógico na educação a distância. In: MILL, D.; RIBEIRO, L. R. C.; OLIVEIRA, M. R. G. (Org.). Polidocência na educação a distância: múltiplos enfoques. São Carlos: EdUFSCar, 2010.

SHULMAN, L. Those who understand: Knowledge growth in teaching. Educational Researcher 15(2), 1986, p. 4-14.

SILVA, M. Cibercultura e educação: a comunicação na sala de aula presencial e online. Revista FAMECOS, $n^{\circ}$ 37. Porto Alegre: Ed. PUCRS, 2008, pp 69-74.

SILVA, J.R. \& LEITÃO, P.D.V. A Situação Comunicativa do Gênero Relato de Experiência de Atuação Profissional. Disponível em: http://www.filologia.org.br/ anais/anais\%20iv/civ04_07-16.html. Acesso 27 set. 2011.

TARDIF, M; RAYMOND, D. Saberes, tempo e aprendizagem do trabalho no magistério. Revista Educação e Sociedade, n 73, PP, 2009-244. São Paulo, 2000.

Data recebimento: $10 / 07 / 2012$ Data aprovação: 16/08/2012 
